\title{
NOVOS CENÁRIOS E VELHOS DEBATES NO CAMPO DA POLÍTICA DE FORMAÇÃO DE PROFESSORES NO BRASIL
}

Sebastiao Silva Soares ${ }^{1}$

\begin{abstract}
RESUMO
O presente artigo, por meio de estudo bibliográfico e documental tem por objetivo propor uma reflexão sobre as reformas empreendidas no campo da formação docente no Brasil a partir da Lei de Diretrizes e Bases da Educação Nacional (LDB) promulgada no ano de 1996 até os dias atuais, com o Plano Nacional de Educação (PNE) e as Novas Diretrizes Curriculares Nacionais para a formação inicial de professores em nível superior e formação continuada (DCNs) e seus possíveis impactos na implementação de políticas para formação docente nos diversos níveis e modalidades de ensino. No estudo foi perceptível que as novas políticas de formação de professores apresentam alguns avanços para a consolidação das políticas de educação no país. No que diz respeito à formação e profissionalização docente, existem lacunas a serem (re)pensadas frente ao prescrito e a materialidade no contexto de prática.
\end{abstract}

Palavras-Chave: Política de formação de professores. Formação inicial. Formação continuada.

\section{NUEVOS CENARIOS Y VELOS DEBATES EN EL CAMPO DE LA POLÍTICA DE FORMACIÓN DE PROFESORES EN BRASIL}

\section{RESUMEN}

El presente artículo, por medio de estudio bibliográfico y documental, tiene por objetivo una reflexión sobre las reformas emprendidas en el campo de la formación docente en Brasil a partir de la Ley de Directrices y Bases de la Educación Nacional (LDB) promulgada en el año 1996, hasta los días con el Plan Nacional de Educación (PNE) y las Nuevas Directrices Curriculares Nacionales para la formación inicial de profesores en nivel superior y formación continuada (DCNs) y sus posibles impactos en la implementación de políticas para formación docente en los diversos niveles y modalidades de enseñanza. En el estudio fue perceptible que las nuevas políticas de formación de profesores presentan algunos avances para la consolidación de las políticas de educación en el país. En lo que se refiere a la formación y profesionalización docente, existen lagunas a ser (re)pensadas frente al prescrito y la materialidad en el contexto de práctica.

Palabras-Clave: Política de formación de profesores. Formación inicial. Formación continua.

\footnotetext{
${ }^{1}$ Doutor pela Universidade de Sevilla - Espanha. Doutorando em Educação pela Universidade Federal de Uberlândia. Mestre em Educação pela Universidade de Brasília. Professor Assistente na Universidade Federal do Tocantins
} 


\section{INTRODUÇÃO}

Vivemos constantes mudanças nas relações sociais com o advento das novas tecnologias digitais e a modernização dos processos produtivos, o que requer mudança de perfis de quadro de profissionais nos diversos setores de trabalho. A educação e o professor tornaram-se elementos fundamentais para o desenvolvimento nacional e o estabelecimento da ordem econômica mundial, particularmente a partir de 1990, em que foi estabelecida uma agenda de reformas educacionais no Brasil dos níveis da educação básica ao ensino superior. (SHIROMA; MORAES; EVANGELISTA, 2011).

Nesse período, a educação, nos países considerados emergentes, sofreu forte influência do financiamento de organismos internacionais, como o Banco Mundial. Um dos fatores de mudanças firmados pelos reformistas na época foi a formação de professores, visando à formação de novas forças de trabalho. É evidente, tanto nos documentos oficiais da época quanto, atualmente, com as novas políticas de formação de professores, a exigência de novos padrões na formação do professor para atender os imperativos do mundo globalizado, em especial na aquisição de técnicas de ensino e o ensinar a fazer na formação do aluno para atuar no mercado de trabalho.

Diante do exposto, buscamos na primeira parte deste trabalho analisar a política de formação de professores no Brasil a partir da Lei de Diretrizes e Bases da Educação Nacional (LDB) de 1996 e seus apontamentos no campo da formação inicial e continuada para os professores no país. Posteriormente, apresentamos uma análise do Plano Nacional de Educação 2014/2014, a fim de ampliar a reflexão com as atuais Diretrizes Curriculares Nacionais para a formação inicial de professores em nível superior e formação continuada (DCNs) e os seus desdobramentos nos currículos dos cursos de licenciatura, nas condições de trabalho dos professores e os impactos possíveis no contexto da prática pedagógica.

Esperamos que este trabalho possa contribuir com novas e velhas reflexões sobre a formação e desenvolvimento profissional do professor no campo das políticas educacionais no país, particularmente, no momento presente em que vivemos as incertezas do ser e estar docente nos cursos de licenciatura. Acreditamos que estudos são necessários nesse contexto de reformas das políticas educacionais no tempo presente, buscando a inserir subsídios e compreensões sobre a política da formação de professores entre o prescrito e materializado no seio das instituições de ensino. 


\section{A POLÍTICA DE FORMAÇÃO DOCENTE NO CONTEXTO DA LDB DE 1996}

Um dos marcos das reformas educacionais no território brasileiro realizada até, hoje, segundo a literatura foi a elaboração e aprovação da nova Lei de Diretrizes e Bases da Educação Nacional (LDB), a Lei n. ${ }^{\circ}$ 9.394, de 20 de dezembro de 1996. Após a aprovação da Lei, as políticas educacionais no Brasil passaram por diversas mudanças e organizações, em especial no que diz respeito à formação inicial, continuada e o desenvolvimento profissional do professor.

Nos artigos n. ${ }^{\circ} 62$ a 65, do Título VI - Dos profissionais da Educação, a LDB/1996 estabelece que a formação de professores para atuar na educação básica far-se-á em nível superior por meio de cursos de licenciaturas em universidades e institutos superiores de educação. A formação de professores, após a aprovação dessa Lei, pode acontecer não somente nas universidades, mas também em Institutos e Faculdades.

Os Institutos Superiores devem promover cursos de formação inicial, continuada e complementação pedagógica para os profissionais da educação em diversos níveis de atuação. Todavia, percebemos, na legislação, uma concepção de "prática desprovida da reflexão, o que parece responder bem às atuais demandas, além de se mostrar pragmaticamente mais eficaz”. (MORAES, 2003, 155).

Nesse ponto, a formação dos professores, conforme a legislação, pode acontecer tanto nos espaços das instituições formadoras como nos locais de trabalho do professor, com a chamada formação em serviço, de modo a desenvolver ainda mais a categoria de competência profissional alicerçada nos imperativos do mercado capitalista, como ilustrado no Artigo 61, parágrafo único, incisos I, II e III da referida Lei:

A formação dos profissionais da educação, de modo a atender às especificidades do exercício de suas atividades, bem como aos objetivos das diferentes etapas e modalidades da educação básica, terá como fundamentos:

I - a presença de sólida formação básica, que propicie o conhecimento dos fundamentos científicos e sociais de suas competências de trabalho;

II - a associação entre teorias e práticas, mediante estágios supervisionados e capacitação em serviço;

III - o aproveitamento da formação e experiências anteriores, em instituições de ensino e em outras atividades. (Grifos Nosso) 
Após 20 anos, reconhecemos que a LDB/1996 representa alguns avanços, como a gestão democrática e a participação dos professores na elaboração do Projeto Político Pedagógico. A legislação direcionou também para os desafios e dilemas sobre a formação do professor na condição de política educacional. Isso porque a formação do professor assume na legislação status de um elemento instrumental e utilitarista, em que o professor deve se responsabilizar de modo individual pela aprendizagem do aluno-trabalhador (KUENZER, 1999). Assim, a tarefa do professor é ensinar o aluno para atuar em diversos contextos do mundo globalizado e as exigências do capital. Nesse sentido, o trabalho desse profissional é considerado uma atividade para atender às demandas emergenciais do capital, ou seja, a categoria trabalho ${ }^{2}$ perde lugar para uma visão de um tecnólogo do ensino. Para Veiga (2009, p. 17), a identidade desse profissional nesse marco histórico:

A) Está intimamente ligada a um projeto de sociedade globalizada e neoliberal e a um modelo de formação que representa uma opção político teórico; B) Parte de um projeto político - educacional maior, de abrangência internacional, com orientações advindas do Banco Mundial; C) com ênfase na chamada educação por resultados, que estabelece padrões rendimentos, alicerçada nos chamados modelos matemáticos, ficando o processo educacional reduzido a algumas variações ligadas à relação custo-benefício; D) Está vinculada, explicitamente, à educação e à produtividade, numa visão puramente economicista.

Nessa perspectiva, o debate educacional focaliza a questão da precarização da formação de professores e os impactos no trabalho docente. Dessa forma, entendemos que pensar a formação e a prática dos professores nessa ótica é apagar "os contextos plurais" que envolvem o processo de ensino (MAGALHÃES; AZEVEDO, 2015, p. 20). Para os autores, é elementar a valorização e reconhecimento do trabalho vivo do professor e o desenvolvimento dos processos de subjetivação e representações na relação professor-aluno.

Segundo os autores, ao atender o paradigma mercadológico, a educação deixa de contribuir o desenvolvimento autônomo e crítico na formação dos alunos. Por isso, há necessidade de buscar políticas educacionais voltadas à valorização da identidade pessoal e profissional do professor, bem como a compreensão da prática docente como trabalho situado, marcado por um contexto discursivo de uma pedagogia internacional hegemônica.

\footnotetext{
${ }^{2}$ A categoria trabalho é entendida aqui como uma ação humana por excelência, pela qual o homem intervém na natureza e em si mesmo como princípio educativo (MANACORDA, 1990).
} 
É possível constatar, no discurso educacional do governo nos anos 1990, uma interdependência entre a qualidade social da educação para todos e a formação do professor. Nessa lógica, a escola assume a tarefa de formar recursos humanos para o mercado (PINHO, 2009). No entanto, ressalvamos que a competência pela competência não é a solução para resolver os problemas da formação profissional, pois o desenvolvimento da competência do ensino e da aprendizagem se tornam elementos aligeirados, fragmentados e desvinculados do contexto (VEIGA, 2009). É possível compreender, a partir da literatura, que a LDB/1996 apresentou uma visão fragmentada de formação inicial e continuada de professor, bem como a reconfiguração do Estado na promoção da educação, privatização e descentralização de processos formativos com a criação dos Institutos Superiores, além da forte influência como um Estado regulador e avaliador das propostas de formação profissional.

Assim, após a promulgação da LDB/1996, diversas emendas foram incluídas ao longo do texto, de modo atender as situações vivenciadas nos diversos níveis e modalidades da educação. Além disso, foram elaboradas e aprovadas, pelo Conselho Nacional de Educação (CNE), diretrizes e estratégias para a efetivação dos direitos educacionais previstos na legislação brasileira, como foi o caso dos Planos Nacionais de Educação e as Diretrizes para os cursos de formação de professores da educação básica, que serão tratados a seguir.

\section{A formação de professores à luz dos Planos Nacionais de Educação (PNEs)}

O Plano Nacional de Educação é um conjunto de metas e estratégias para a educação nacional, por um período de 10 anos para sua execução. Segundo Saviani (2004), a ideia do Plano retoma as ideias iniciais dos Pioneiros da Educação de 1932, as quais visaram a um esboço para a elaboração de um plano nacional de educação no país.

No Brasil, após a promulgação da Constituição Federal de 1988, foram elaborados dois planos em formato de lei, instituído pela Lei n. ${ }^{\circ} 10.172$, de 09 de janeiro de 2001, composto por objetivos, diretrizes e metas em cada nível de ensino. Embora alguns autores tenham reduzido a ideia desse Plano a uma carta de intenção, o texto de acompanhamento que propôs a criação de um novo plano reconheceu que o Documento "contribuiu para a construção de políticas e programas voltados à melhoria da educação, muito embora tenha 
vindo desacompanhado dos instrumentos executivos para a consecução das metas por ele estabelecidas" (BRASIL, 2014, p. 14).

Apesar de todo o esforço, o antigo plano apresentou vários problemas na sua formulação e execução, em especial no conjunto de metas quantitativas, financiamento e a falta de estratégias para o cumprimento das metas estabelecidas (DOURADO, 2010). No caso específico da formação de professores, o plano suscitou alguns dilemas. Houve uma supervalorização nas áreas das Ciências e Matemática em detrimento de outras áreas do conhecimento, o encaminhamento da formação de professores da educação básica passa ser também realizada na modalidade à distância.

O novo PNE 2014/2024, promulgado pela Lei n. ${ }^{\circ} 13.005 / 2014$, é composto por 20 metas e 254 estratégias em diretrizes, objetivos, níveis de ensino e temas. Existem questões relacionadas à educação especial, tempo integral, qualidade da educação básica e superior, educação de jovens e adultos integrada à educação profissional, educação profissional e técnica, ensino superior, formação inicial e continuada dos profissionais da educação, valorização profissional da educação, gestão democrática e financiamento, dentre outros (BRASIL, 2014).

Conforme o texto de apresentação do Plano, aprovado por meio de debates com a presença de vários segmentos, com velhos e novos autores, o foco maior dos debates foram o Fundo de Manutenção e Desenvolvimento da Educação Básica e de Valorização dos Profissionais da Educação (FUNDEB). O novo plano apresenta alguns avanços em relação à legislação anterior, especificamente, na valorização dos povos tradicionais e seu processo de escolarização, a formação de professores para a educação do campo, indígenas e quilombolas, educação inclusiva, o uso das novas tecnologias na prática pedagógica e outros. No que diz respeito à formação de professores e desenvolvimento dos profissionais da educação, o novo PNE apresenta especificamente as seguintes metas:

Meta 15: garantir, em regime de colaboração entre a União, os Estados, o Distrito Federal e os Municípios, no prazo de 1 (um) ano de vigência deste PNE, política nacional de formação dos profissionais da educação de que tratam os incisos I, II e III do caput do art. 61 da Lei n..$^{\circ}$ 9.394, de 20 de dezembro de 1996, assegurado que todos os professores e as professoras da educação básica possuam formação específica de nível superior, obtida em curso de licenciatura na área de conhecimento em que atuam. 
Meta 16: formar, em nível de pós-graduação, $50 \%$ (cinquenta por cento) dos professores da educação básica, até o último ano de vigência deste PNE, e garantir a todos (as) os(as) profissionais da educação básica formação continuada em sua área de atuação, considerando as necessidades, demandas e contextualizações dos sistemas de ensino.

Meta 17: valorizar os(as) profissionais do magistério das redes públicas de educação básica, de forma a equiparar seu rendimento médio ao dos(as) demais profissionais com escolaridade equivalente, até o final do sexto ano de vigência deste PNE.

Meta 18: assegurar, no prazo de 2 (dois) anos, a existência de planos de carreira para os (as) profissionais da educação básica e superior pública de todos os sistemas de ensino e, para o plano de carreira dos (as) profissionais da educação básica pública, tomar como referência o piso salarial nacional profissional, definido em lei federal, nos termos do inciso VIII do art. $206 \mathrm{da}$ Constituição Federal. (BRASIL, 2014).

Na análise da Meta 15, percebemos que ela está articulada diretamente com a política de formação de professores da educação básica, o programa PARFOR. Esse programa visa atender as disposições do Decreto n. ${ }^{\circ}$ 6.755, que institui a Política Nacional de Formação de Profissionais do Magistério da Educação Básica, disciplina a atuação da Coordenação de Aperfeiçoamento de Pessoal de Nível Superior (CAPES) e os dispostos da LDB/1996.

Nessa perspectiva, a proposta do PARFOR é oferecer formação inicial para os professores que já atuam no contexto da educação básica por meio do regime de colaboração entre a União, os Estados, Distrito Federal e Municípios (BRASIL, 2009). Assim, o programa é uma ação emergencial, cuja prioridade é atender aos professores atuantes, além disso, oferecer a segunda licenciatura e a complementação pedagógica para os professores não licenciados. Todavia, a meta não apresenta algo novo, visto que o próprio programa foi criado antes da aprovação do plano. Acreditamos que a meta 15 ratifica a urgência de política de formação de professores no país, em especial no contexto da educação básica, que carece de profissionais em diversas áreas do conhecimento (GATTI, 2009).

As estratégias para a execução da meta 15 direcionam para programas formulados e em processo de implementação no campo da política de formação de professores no país, tais como: Programa Institucional de Bolsa de Iniciação à Docência, Programa de Consolidação das Licenciaturas, Pró-letramento, Pacto Nacional pela Alfabetização na Idade Certa, Pacto Nacional de Fortalecimento do Ensino Médio, Universidade Aberta do Brasil, dentre outros. No entanto, um ponto de desafio evidenciado nas metas acima é a construção do regime de 
colaboração, visto que não é explicitada como ocorrerá o regime de colaboração entre os entes da federação.

Afirmamos isso devido aos diversos problemas, como, por exemplo, a dificuldade financeira das Prefeituras e Estados para pagar o Piso Salarial Nacional dos Professores estabelecido em Lei, quanto mais investir na formação inicial e continuada dos professores, conforme informações ${ }^{3}$ divulgadas, em 2016, pela Confederação Nacional dos Trabalhadores em Educação (CNTE). Todavia, a formação de professores não pode ser vista como "pacote fechado" e emergencial, é necessário e urgente formular políticas permanentes de formação dos professores, visando à valorização da pessoa e profisssional do professor. Em outras palavras:

\begin{abstract}
A formação não se constrói por acumulação (de cursos, de conhecimentos ou de técnicas), mas sim através de um trabalho de reflexividade crítica sobre as práticas e de (re)construção permanente de uma identidade pessoal. Por isso é tão importante investir na pessoa e dar estatuto ao saber da experiência. (NÓVOA, 1995, p.25).
\end{abstract}

Além disso, é crucial também a compreensão que a prática pela prática não responde às necessidades dos professores, pois a formação e o trabalho docente sem o movimento da práxis "denotam o silêncio e o esquecimento, a calada que envolve a aceitação acrítica da lógica do capital, não obstante a violência econômica e a destruição social e cultural efetivada por sua vanguarda" (MORAES, 2003, p. 164). Assim, a formação do professor não pode ser desvinculada de um olhar crítico e epistemológico. Precisamos superar a formação docente como receita e treinamentos aligeirados, a fim de estabelecer o estatuto profissional do ser professor.

Dourado (2015, p. 306) avalia que o PNE e as Diretrizes Curriculares Nacionais para a Formação Inicial e Continuada, em Nível Superior, aprovada pela Resolução 2015/02 (assunto que será tratado no próximo tópico desta seção), e as Diretrizes Curriculares Nacionais para a Educação Básica implicam repensar e avançar nos debates acerca da formação inicial dos professores no país, "por meio de ações mais orgânicas entre as políticas e gestão para a educação básica e a educação superior, incluindo a pós-graduação e políticas 3 Informações obtidas em: http://agenciabrasil.ebc.com.br/educacao/noticia/2016-03/mais-da-metade-dos-
estados-nao-paga-o-piso-salarial-aos-professores-diz. Acesso em 10 de jul. de 2016. 
direcionadas à valorização dos profissionais da educação". Dourado (2015) também reconhece os avanços que as metas e estratégias que o PNE apresenta, porém sinaliza para a necessidade do diagnóstico e avaliação permanente entre diversas instâncias e agentes promotores pela formulação e implementação das propostas de formação para os profissionais da educação e assim finaliza:

Faz-se necessário instituir o Sistema Nacional de Educação, consolidar Política Nacional para a formação dos profissionais da educação, estabelecer diretrizes curriculares nacionais para a carreira e garantir novos recursos visando cumprir a meta de $10 \%$ do PIB para a educação, entre outros, como processos articulados e fundamentais a maior organicidade para as políticas e gestão da educação nacional. (DOURADO, 2015, p. 316).

A meta 16 do PNE trata da formação de professores da educação básica em nível de pós-graduação lato sensu e stricto sensu. A proposta veiculada pela meta é estabelecer propostas de formação com base nas demandas, necessidades de cada região, por meio do regime de colaboração entre os entes federados. A meta 16 apresente alguns avanços no campo da formação de professores, como o fomento de oferta de cursos de pós-graduação aos professores da educação básica ${ }^{4}$, assim como (re)pensar a articulação na oferta dos cursos entre os entes, maior participação do corpo docente na elaboração das propostas, garantia de acesso e permanência dos docentes nos cursos, avaliação dos ofertados e das instituições formadoras.

Nessa direção, compreendemos que muitas das ideias expostas nas metas do PNE apresentam uma lógica estrutural em torno das parcerias público e privado "baseando-se na política de responsabilização educacional fundamentada na meritocracia e na distribuição de bônus e incentivos a escolas, gestores e comunidade escolar com melhor desempenho nas provas nacionais" (FREITAS, 2014, p. 439). A autora afirma que diversos segmentos têm disputado o mercado educacional, na promoção e acúmulo do capital com a oferta de cursos de formação continuada fragmentados e descontextualizados da realidade social da educação vivenciada pelos profissionais da educação. Portanto:

\footnotetext{
${ }^{4}$ Antes da aprovação do novo PNE, foram implantados diversos cursos de formação continuada dos professores, em especial por meio da Universidade Aberta do Brasil, na modalidade a distância, além de programas de mestrados profissionais em rede para os professores da educação básica (PROEB), por meio da Portaria n. ${ }^{\circ}$ 209, de 21 de outubro de 2011. Para melhores informações, acesse o site: http://www.capes.gov.br.
} 
A implementação dessas ações vem se dando em um campo acentuado de disputas e debate de ideias de concepções diferenciadas e antagônicas que acentuam processos de regulação da formação, do trabalho, das habilidades, atitudes, modelos didáticos e capacidades dos professores, na direção de um rebaixamento das exigências científicas e técnicas dos percursos formativos, em oposição a proposições que, em resistência, lutam para situar a formação de professores em patamares cada vez mais elevados, em sintonia com as transformações sociais, científicas e técnicas demandadas por um projeto educativo de caráter sócio-histórico emancipador. (FREITAS, 2014, p. 440).

As metas e estratégias no PNE, de modo especial no campo da formação de professores, representam alguns desafios, principalmente no planejamento e execução, visto que a reforma nos currículos é sinal de progresso e desenvolvimento social do país articulados com os interesses dos organismos internacionais (VEIGA; QUIXADÁ VIANA, 2012). Isso impõe outro olhar sobre as forças antagônicas que perpassam as propostas da formação de professores no país e os impactos na vida pessoal do professor e na prática pedagógica.

Nessa perspectiva, a meta 17 representa ganho e desafio na valorização do trabalho docente. Segundo o Documento, é fundamental a valorização dos profissionais da educação básica e o rendimento financeiro equivalente aos profissionais com o mesmo nível de formação. É evidente, nessa meta, a preocupação sobre os ganhos financeiros dos professores. No entanto, as estratégias adotadas pela execução da meta exigem a construção de fóruns permanentes com representação de vários segmentos para acompanhar a evolução salarial dos professores, o que retoma a proposta do regime de colaboração e seus desafios na consolidação do quadro de políticas educacionais.

Sobre isso, a meta 18 coloca como referência o piso nacional dos professores, sendo que este "está aquém não só do desejável, mas também daquilo que vem sendo considerado, por setores da sociedade, como patamares aceitáveis para se imprimir valorização a estes profissionais" (JACOMINI; ALVES; CAMARGO, 2015, p. 02), principalmente em relação aos profissionais docentes de outros países. As disposições das metas reforçam a necessidade de estabelecer a valorização da profissão do professor e a elaboração do plano de carreira, conforme estabelecido na meta 18 do PNE.

Entendemos que não é apenas a formação do professor que poderá garantir a qualidade social da educação, uma vez que existem outras variáveis históricas, políticas, econômicas sociais e culturais que interferem na formação e desenvolvimento da prática pedagógica. Desse modo, ratificamos a necessidade de articular os debates sobre a formação e 
o trabalho do professor como profissional. Ademais, é imprescindível o domínio do conteúdo, das teorias pedagógicas e a garantia de melhores condições de trabalho na constituição da identidade pessoal e profissional do professor.

Acreditamos que ações assumidas nessa direção poderão despertar o interesse dos alunos das licenciaturas pela docência, conforme estabelecido nas estratégias: 18.2, 18.3, 18.4 do PNE, além de valorizar o trabalho dos professores na ativa e o respeito por eles na condição de categoria profissional. É fundamental que haja garantia de benefícios, como a previsão de licenças renumeradas, incentivo para a qualificação e a reestruturação e implantação dos planos de carreira docente:

[...] É preciso investir na valorização do profissional dignificando o trabalho pedagógico e a carreira docente, melhorar suas condições de trabalho, estimular a organização coletiva dos profissionais em entidades sindicais, científicas, entre outras. (VEIGA, 2009, p. 20).

Nessa ótica, a formação e a profissionalização dos professores são elementos centrais que devem ser refletidos no processo da formulação e implantação das políticas de educação, a fim de superar a visão limitadora de qualquer pessoa que domine determinado conhecimento técnico do ser professor (KUENZER, 1999). Portanto, pensar a formação docente à luz das metas e estratégias presentes no PNE exige a compreensão de que política nacional é mais abrangente do que a própria legislação, principalmente quando pensamos no contexto da política educacional (MAINARDES, 2006). Nesse sentido, um dos mecanismos criados para a efetivação das metas e estratégias definidas no PNE 2014/2024 acerca da formação e valorização dos profissionais do magistério da educação foram as Diretrizes Curriculares Nacionais para a formação inicial de professores em nível superior e a formação continuada, conforme veremos a seguir.

\section{Diretrizes Curriculares Nacionais para a formação inicial de professores em nível superior e formação continuada (DCNs): implicações na formação docente}

Ao analisar as Novas Diretrizes Curriculares Nacionais para a Formação Inicial e Continuada dos Profissionais do Magistério da Educação Básica (DCNs), aprovadas pela 
Resolução 2015/02, são perceptíveis algumas mudanças no campo da sua abrangência em relação à Resolução CNE/CP n. ${ }^{\circ}$ 1/2002, que instituía no país as Diretrizes Curriculares Nacionais para a Formação de Professores da Educação Básica, em nível superior, em curso de licenciatura e de graduação plena.

No caso da nova Resolução, é disposto, no Art. n. ${ }^{\circ}$ 09, que os cursos de formação para os profissionais do magistério da educação básica em nível superior compreendem-se: I cursos de graduação de licenciatura; II - cursos de formação pedagógica para graduados não licenciados; III - cursos de segunda licenciatura (BRASIL, 2015). Isso porque a antiga Resolução apresentava uma abrangência menor, em nível superior, com curso de licenciatura e graduação plena.

Além da licenciatura mencionada na legislação anterior, a nova Resolução instituiu que os profissionais poderão ingressar em cursos de formação inicial docente por meio da segunda licenciatura direcionada a profissionais licenciados, independentemente da sua área de formação, e complementação pedagógica para graduados não licenciados, ofertados aos formados em cursos relacionados à habilitação pretendida. Assim, a Resolução, no Art. n. ${ }^{\circ}$ 13, dispõe:

$\S 2^{\circ}$ Os cursos de formação deverão garantir nos currículos conteúdos específicos da respectiva área de conhecimento ou interdisciplinares, seus fundamentos e metodologias, bem como conteúdos relacionados aos fundamentos da educação, formação na área de políticas públicas e gestão da educação, seus fundamentos e metodologias, direitos humanos, diversidades étnico-racial, de gênero, sexual, religiosa, de faixa geracional, Língua Brasileira de Sinais (Libras), educação especial e direitos educacionais de adolescentes e jovens em cumprimento de medidas socioeducativas.

$\S 3^{\circ}$ Deverá ser garantida, ao longo do processo, efetiva e concomitante relação entre teoria e prática, ambas fornecendo elementos básicos para 0 desenvolvimento dos conhecimentos e habilidades necessários à docência. (BRASIL, 2015).

Nesse ínterim, a Resolução prevê que a formação inicial do professor deve ir além de um conhecimento específico, torna-se vital considerar a docência como ação educativa e como processo pedagógico intencional e metódico, que envolve conhecimentos específicos, interdisciplinares e pedagógicos. Desse modo, os currículos dos cursos direcionados à formação de professores não podem excluir em suas diretrizes as dimensões éticas, sociais, científicas e filosóficas. 
A Resolução explícita a valorização concomitante da relação teoria e prática, a fim de diminuir o distanciamento desse processo na formação do professor, nos cursos de licenciatura, e a sua atuação na educação básica. Assim, as diretrizes apontam que a relação teoria e prática são eixos separados da formação docente, exigindo dos cursos uma relação entre a teoria e prática na formação do professor. Todavia, numa concepção dialética do conhecimento, existe, na verdade, nesse processo, a indissociabilidade entre a teoria e prática (VÁSQUEZ, 1968). Gatti (2010, p. 1372), ao analisar os currículos e ementas de alguns cursos de licenciatura no país, constatou:

Nas ementas observou-se um evidente desequilíbrio na relação teoria-
prática, em favor dos tratamentos mais teóricos, de fundamentos política e
contextualização e que a escola, como instituição social e ensino, é elemento
quase ausente nas ementas, o que leva a pensar numa formação de caráter
mais abstrato e pouco integrado ao contexto concreto onde o profissional-
professor vai atuar.

Nesse sentido, os estudos da pesquisadora evidenciam as fragilidades pedagógicas e específicas que os cursos de formação de professores apresentam em seus currículos, em particular a ideia da escola ideal prescrita nos documentos em detrimento da escola real vivenciada pelo docente. Para a autora, é fundamental uma revolução nas estruturas institucionais e formativas, de modo a integrar a universidade e os centros de formação com a escola básica e desenvolvimento formativo do professor, ideal também explícito nas DCNs.

Outro ponto de análise das novas Diretrizes diz respeito à formação de professores para atuarem em todos os níveis e modalidades, da educação básica ao ensino superior, com destaque para as modalidades da Educação de Jovens e Adultos, Educação Especial, Educação Profissional e Tecnológica, Educação do Campo, Educação Indígena, Educação Quilombola e Educação a Distância. Essa proposta das modalidades educacionais nas DCNs pode ser justificada pela perspectiva de educação pautada na diversidade, nos direitos humanos e na inclusão, defendida e aprovada no PNE/2014-2024, exposto anteriormente, e os debates em torno da diversidade cultural na ótica do multiculturalismo em voga:

O projeto multicultural, por sua vez, insere-se em uma visão pós-moderna de sociedade, em que a diversidade, a descontinuidade e a diferença são percebidas como categorias centrais. Da mesma forma, contrapondo-se à percepção moderna e iluminista da identidade como uma essência, estável e fixa, o multiculturalismo percebe-a como descentrada, múltipla e em 
processo permanente de construção e reconstrução (CANEN; OLIVEIRA, 2002, p. 62-63).

No campo da formação de professores, as autoras acreditam que essa abordagem possibilita pensar a diversidade cultural que os alunos apresentam em sala de aula, ou seja, que a identidade, a diversidade e a diferença sejam pensadas como eixo de reflexão crítica e reconstrução de um currículo ainda fragmentado, excludente e preconceituoso que permeia ainda a maioria das práticas pedagógicas das instituições e dos professores. Na mesma dimensão, Silva (2012) ressalta a importância de currículo e uma pedagogia da diferença, de modo a ampliar o olhar crítico dos professores em torno de uma prática pedagógica, inserida num contexto de mudança, instabilidade, ambíguo e multicultural:

Uma política pedagógica e curricular da identidade e da diferença tem a obrigação de ir além das benevolentes declarações de boa vontade para com a diferença. Ela tem que colocar no seu centro uma teoria que permita não simplesmente reconhecer e celebrar a diferença e a identidade, mas questioná-las (SILVA, 2012, p. 100).

Outra alteração relevante diz respeito à carga horária mínima das licenciaturas que teve o acréscimo de 400 horas, passando de 2.800 para 3.200 horas. Assim, o tempo mínimo para conclusão do curso de licenciatura passa a ser de 8 semestres/4 anos, conforme o Art. 13 e o respectivo inciso e parágrafos:

$\S 1^{\circ}$ Os cursos de que trata o caput terão, no mínimo, 3.200 (três mil e duzentas) horas de efetivo trabalho acadêmico, em cursos com duração de, no mínimo, (oito) semestres ou 4 (quatro) anos, compreendendo:

I - 400 (quatrocentas) horas de prática como componente curricular, distribuídas ao longo do processo formativo;

II - 400 (quatrocentas) horas dedicadas ao estágio supervisionado, na área de formação e atuação na educação básica, contemplando também outras áreas específicas, se for o caso, conforme o projeto de curso da instituição;

III - pelo menos 2.200 (duas mil e duzentas) horas dedicadas às atividades formativas estruturadas pelos núcleos definidos nos incisos I e II do artigo 12 desta Resolução, conforme o projeto de curso da instituição. (BRASIL, 2015).

Nessa dimensão, foi instituída nas novas DCNs uma reformulação na carga horária nos cursos de formação inicial para o magistério, além da valorização da diversidade nacional, dos direitos humanos e autonomia das instituições formativas e a atuação e participação na 
organização e gestão de sistema de educação básica e suas instituições. No caso dos professores formadores nas licenciaturas prevê um projeto de organização institucional para a formação dos formadores, incluindo tempo e espaço na jornada de trabalho para as atividades coletivas, estudo e a investigação sobre o aprendizado dos professores, além das atividades de criação e apropriação culturais junto aos formadores e futuros professores.

Todavia, a legislação não estabelece metas e normativas acerca da formação do formador e o seu trabalho com os futuros professores. No que concerne à formação continuada, para os profissionais do magistério da educação básica, a legislação institui, no âmbito do Art. n. ${ }^{\circ}$ 16, que esta deverá ocorrer por meio de cursos de atualização, aperfeiçoamento, extensão, especialização, mestrado e doutorado.

Para isso, a presente legislação propõe que essa formação deve ser decorrente de uma concepção de desenvolvimento profissional "agregação de saberes e práticas, articulando às políticas e gestão da educação, à área de atuação do profissional e às instituições de educação básica” (BRASIL, 2015). Assim, evidenciamos que as novas DCNs visam assegurar e efetivar as Metas e Estratégias do PNE 2014-2024 e demais legislações no âmbito da formação inicial e continuada dos profissionais do magistério. Em síntese:

$\mathrm{Na}$ busca de maior organicidade das políticas, as novas DCNs enfatizam que estes processos implicam o repensar e o avançar nos marcos referenciais atuais para a formação inicial e continuada por meio de ações mais orgânicas entre as políticas e gestão para a educação básica e a educação superior, incluindo a pós-graduação e, nesse contexto, para as políticas direcionadas à valorização dos profissionais da educação (DOURADO, 2015, p. 306).

Pensar a formação do professor no âmbito dessas normativas é buscar inserir a formação docente muito além de um currículo fechado e fragmentado, é essencial desenvolver ações formativas que valorizem os saberes e as experiências do professor em formação inicial e continuada. Entretanto, não é possível estabelecer uma formação docente da prática pela prática como mecanismo de melhoria da educação.

É preciso criar espaços e oportunidades formativas que articulem, de modo integrado, a relação teoria-prática, da universidade e escola, da escola e a universidade. Além disso, para assegurar a efetivação das Diretrizes, é basilar a promoção do regime, em colaboração entre os entes federados da educação e as instituições formativas, visando assim à defesa da educação como direito social e humano. 


\section{CONSIDERAÇÕES FINAIS}

Por meio do estudo em tela, foi possível perceber que a formação de professores no campo da política educacional tem sido desenvolvida numa contexto marcado de interesses e relações de poder. $\mathrm{Na}$ análise das legislações, particularmente, no aspecto comparativo, notamos que ambos dos documentos apresentam avanços e retrocessos no campo da formação do docente. Foi perceptível que a formação dos professores ainda é compreendida como eixo estratégico do governo para formar novas mãos de obra para o mercado de trabalho. Além disso, as políticas educacionais estão sob a égide dos interesses de uma classe dominante, visto que muitas das ações apresentadas por essas políticas estão articuladas aos interesses do capital empresarial.

Nesse ponto, a educação, como proposta formativa torna-se uma ação neutra sem apresentar uma preocupação com as questões sociais, culturais e ideológicas que perpassam o processo de ensino-aprendizagem e o desenvolvimento profissional docente. Inferimos pelas legislações em vigor, que o importante da ação educativa é a formação de forças de trabalho visando à mobilização de estratégias, habilidades e competências para contexto mercadológico.

Não encontramos nas propostas uma valorização direta da pessoa do professor e seus saberes. Ou seja, as relações intersubjetivas e culturais que impactam na identidade do professor e seu desenvolvimento pedagógico, são reconhecidos apenas como elemento de inclusão dos alunos, sem debater as implicações qualitativas de como essas concepções podem influenciar no fazer diário do professor em sala de aula e na escola. Em outras palavras, o professor ainda é o profissional que apenas está para executar determinada atividade do ensino, pois apesar de ambas as legislações defenderem a ideia da gestão democrática, não vimos como isso poderá ser realizado a fim de valorizar o professor e seus saberes construídos no chão da escola, bem como os saberes do currículo na sua dimensão crítica.

Nesse sentido, o momento atual é um espaço/tempo propício para analisar e refletir sobre o andamento das políticas de formação de professores no país, pois novas ações do governo estão sendo apresentadas e implementadas no cotidiano escolar e universitário sem a participação diretas de professores, alunos e comunidade em geral, como é o caso da Base 
Nacional Comum Curricular do Ensino Fundamental e Médio (BNCC), bem como a proposta da Residência Pedagógica, frutos de muitas ideias apresentadas no corpus das referidas legislações analisadas por nós.

Por fim, acreditamos que a formação do professor e a melhoria da sua prática não ocorrem de modo fragmentado e acabado, é fundamental a compreensão que a formação do professor é um processo complexo, que envolve não apenas as relações das demandas da sala de aula, mas acima de tudo que haja o reconhecimento e valorização profissional da pessoa do professor. É necessário também que os governantes e representantes da sociedade civil, com a participação direta de professores promovam no campo das políticas de educação, uma formação docente contrária à lógica do capital, preocupada primeiramente em contribuir com a emancipação do aluno como sujeito social e crítico.

\section{REFERÊNCIAS}

BRASIL. Lei no 13.005, de 25 de junho de 2014. Aprova o Plano Nacional de Educação PNE e dá outras providências. Diário Oficial da União, Brasília, DF, 26 jun. 2014.

. Lei 9.394, de 1996. Regulamenta as Diretrizes e Bases da Educação Nacional. Diário Oficial [da] República Federativa do Brasil, Brasília, 1996.

Conselho Nacional de Educação. Conselho Pleno. Resolução no 2/2015. Define as Diretrizes Curriculares Nacionais para a formação inicial em nível superior (cursos de licenciatura, cursos de formação pedagógica para graduados e cursos de segunda licenciatura) e para a formação continuada. Brasília, DF: CNE.

CANEN, Ana; OLIVEIRA, Ângela, M.A. Multiculturalismo e currículo em ação: um estudo de caso. Revista Brasileira de Educação., Set/Out/Nov/Dez 2002, n. 21. Disponível em: <http://www.scielo.br/pdf/rbedu/n21/n21a05.pdf/>. Acesso em 10 de abril de 2015.

DOURADO, Luiz Fernandes. Avaliação do Plano Nacional de Educação 2001-2009: questões estruturais e conjunturais de uma política. Educação e Sociedade., Campinas, v. 31, n. 112, p. 677-705, jul./set. 2010. Disponível em: 〈http://www.scielo.br/pdf/es/v31n112/03.pdf $>$. Acesso em 15 de junho de 2017.

. Diretrizes curriculares nacionais para a formação inicial e continuada dos profissionais do magistério da educação básica: concepções e desafios. Educação e Sociedade, Campinas, v. 36, nº. 131, p. 299-324, abr.-jun., 2015. Disponível: <http://dx.doi.org/10.1590/ES0101-73302015151909 >. Acesso em 15 de junho de 2017.

FREITAS, Luiz Carlos de. Os reformadores empresariais da educação e a disputa pelo controle do processo pedagógico na escola. Educação e Sociedade., Campinas, v. 35, nº 129 , 
p. 1085-1114, out.-dez., 2014. Disponível em: <http://www.scielo.br/pdf/es/v35n129/01017330-es-35-129-01085.pdf $>$. Acesso em 17 de junho de 2017.

GATTI, Bernadete Angelina; BARRETO, Elba Siqueira de Sá. Professores do Brasil: impasses e desafios / Coordenado por Bernadete Angelina Gatti e Elba Siqueira de Sá Barreto. - Brasília: UNESCO, 2009.

Formação de professores no Brasil. Características e problemas. Educação e Sociedade., Campinas, v 31, n. 113, p. 1355-1379, out,-dez.2010. Disponível em: <http://www.scielo.br/pdf/es/v31n113/16.pdf>. Acesso em 10 de maio de 2017.

JACOMINI, Márcia Aparecida; ALVES, Thiago; CAMARGO, Rubens Barbosa de. Plano Nacional de Educação e remuneração docente: desafios para o monitoramento da valorização profissional no contexto da meta 17. Anais da $37^{\mathrm{a}}$ Reunião Nacional da ANPEd - 04 a 08 de outubro de 2015, UFSC - Florianópolis.

KUENZER, Acácia. Z. As políticas de formação: a constituição da identidade do professor sobrante., Educação e Sociedade, Campinas, v. 20, n. 68, p.163-183, dez. 1999. Disponível em: <http://dx.doi.org/10.1590/S0101-73301999000300009>. Acesso em 22 de junho de 2017.

MAGALHÃES, Lígia Karam Corrêa; AZEVEDO, Leny Cristina Soares Souza. Formação continuada e suas implicações: entre a lei e o trabalho docente. Caderno Cedes., Campinas, v. 35, n. 95, p. 15-36, jan.-abr, 2015. Disponível em:

$\langle$ http://www.scielo.br/pdf/ccedes/v35n95/0101-3262-ccedes-35-95-00015.pdf $>$. Acesso em 26 de junho de 2016.

MAINARDES, Jefferson. Abordagem do ciclo de políticas: Uma contribuição para a análise de políticas educacionais., Educação e Sociedade, Campinas, vol. 27, n. 94, p. 47-69, jan./abr, 2006. Disponível em: 〈http://www.scielo.br/pdf/es/v27n94/a03v27n94.pdf >. Acesso em 10 de julho de 2015.

MANACORDA, Mario Alighiero. O princípio educativo em Gramsci. Porto Alegre: Artes Médicas, 1990.

MORAES, Maria Célia Marcondes. (Org.). Iluminismo às avessas: produção de conhecimento e políticas de formação docente. Rio de Janeiro: DP\&A, 2003.

NÓVOA, António. Formação de professores e profissão docente. In: NÓVOA, António (org.). Os professores e a sua formação. 2. ed. Lisboa: Dom Quixote, 1995. p.13-33.

PINHO, Maria. José de; GUIMARÃES, Valter Soares; MAGALHÕES, Solange M. O; SOUZA, Ruth Catarina Cerqueira Ribeiro de; TOSCHI, Mirza Seabra. Políticas de formação de professores: a continuidade de um processo iniciado na década de 1990 - Aonde vamos chegar? In: Valter Soares Guimarães. (Org.). Formação e Profissão docente: cenários e propostas. 1ed. Goiânia: Ed. da UCG, 2008, v. 1, p. 1-222. 
SAVIANI, Demerval. Da nova LDB ao novo plano nacional de educação: por uma outra política educacional. Campinas, SP: Autores Associados, 2004.

SHIROMA, Eneida Oto; MORAES, Maria Célia Marcondes de; EVANGELISTA, Olinda. Política Educacional. Rio de Janeiro: Lamparina, 4 ed., 2011.

SILVA, Tomaz Tadeu da. A produção social da identidade e da diferença. In: SILVA, Tomaz Tadeu da (Org.). Identidade e diferença: a perspectiva dos estudos culturais. Petrópolis: Vozes. 2000. p. 73-102.

VASQUEZ, A. S. Filosofia da práxis. São Paulo: expressão popular, 1968.

VEIGA, Ilma. Passos. Alacastro. Docência como atividade profissional. In: VEIGA, I. P. A.; D’AVILA, C. (Org.). Profissão docente: novos sentidos, novas perspectivas. 2. ed. Campinas: Papirus, 2009.

; QUIXADÁ VIANA, Cleide Maria. Formação de professores: um campo de possibilidades inovadoras. In: VEIGA; Ilma Passos Alencastro; SILVA, Edileuza Fernandes da (Org). A escola mudou. Que mude a Formação de professores! Campinas: Papirus, 2012. 